\title{
SHOT PEENING MESIN OTOMATIS PADA MATERIAL PESAWAT TERBANG AL 7050-T7651 MENURUNKAN LAJU PERAMBATAN RETAK FATIK DIBANDING SHOT PEENING MESIN MANUAL
}

\author{
Haris Ardianto \\ Teknik Dirgantara \\ Sekolah Tinggi Teknologi Kedirgantaraan STTKD Yogyakarta \\ Jl. Parangtritis Km. 4,5 Yogyakarta PO BOX 1242 \\ Email : haris.ardianto@gmail.com
}

\begin{abstract}
Perlakuan permukaan shot peening paling banyak diaplikasikan untuk meningkatkan ketahanan fatik dan korosi pada konstruksi pesawat terbang. Penelitian ini bertujuan untuk mempelajari pengaruh shot peening mesin otomatis terhadap laju perambatan retak fatik pada material Al 7050-T7651 serta membandingkannya dengan shot peening mesin manual. Spesimen dibentuk sesuai dengan standar ASTM E647, diidentifikasi dengan nama base metal shot peenedautomatic machine (BMSPA). Proses perlakuan shot peening dilakukan di area surface treatment PT. Dirgantara Indonesia menggunakan mesin otomatis. Selanjutnya pengujian perambatan retak fatik dilakukan dengan mesin Servopulser di Lab. Bahan Teknik Jurusan Teknik Mesin UGM, dengan beban sekitar 11\% dari tegangan tarik maksimum (spesimen standar ASTM E8M) yang dihubungkan dengan analisis beban kombinasi, dengan stress ratio $R=0,1$. Data hasil uji tersebut diolah menggunakan metode incremental polynomial untuk mendapatkan hubungan da/dN - $A K$. Hasil uji perambatan retak fatik menghasilkan angka konstanta Paris $A=1,874 \times 10^{-8}$ dan $n=1,06$ jika dibandingkan hasil penelitian sebelumnya untuk spesimen $A R$ as received material-tanpa perlakuan dengan $A=1,288 \times 10^{-9}$ dan $n=2,02$; dan BMSP base metal shot peened-manual machine dengan $A=1,286 \times 10^{-9}$ dan $n=2,01$. Semakin rendah nilai konstanta Paris, menunjukkan semakin rendahnya laju perambatan retak fatik. Sehingga perlakuan shot peening dengan mesin otomatis lebih mampu menurunkan laju perambatan retak fatik daripada mesin manual atau tanpa perlakuan.
\end{abstract}

Keywords : fatik, shot peening, konstanta Paris

1. Pendahuluan

Pembebanan tegangan tarik, tekan, bending atau kombinasinya secara berulang atau siklik ketika pesawat terbang beroperasi semakin lama, akan menyebabkan terjadinya kegagalan lelah atau fatik. Kegagalan fatik (fatigue failure) merupakan salah satu kegagalan yang umumnya ditemukan pada komponen pesawat terbang, otomotif dan konstruksi mesin serta peralatan yang mengalami beban dinamis. Salah satu upaya untuk meningkatkan fatigue life dalam rangka menanggulangi kegagalan fatik adalah dengan cara memberi compressive residual stress (tegangan sisa tekan), yang salah satunya melalui proses shot peening.
Komponen-komponen pesawat terbang dan karakteristik material yang harus dipenuhi, ditunjukkan dalam gambar 1 .

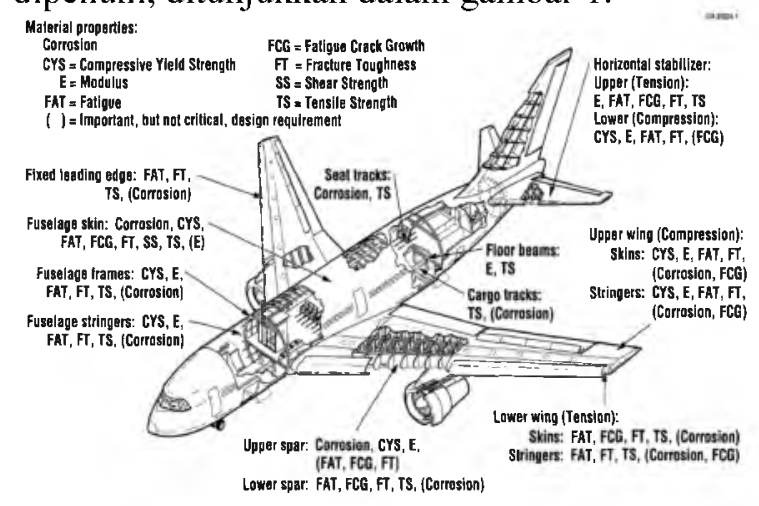

Gambar 1. Komponen pesawat terbang dan karakteristik material [1]

Berdasarkan ASTM standard E647, laju perambatan retak fatik dihitung menggunakan persamaan Paris [2] : 


$$
\begin{aligned}
& \frac{d a}{d N}=A(\Delta K)^{n} \ldots \ldots(1) \\
& \left(\frac{d a}{d N}\right)=\frac{b_{1}}{A_{2}}+2 b_{2}\left(\frac{N_{i}-A_{1}}{A_{2}}\right) \ldots \ldots
\end{aligned}
$$

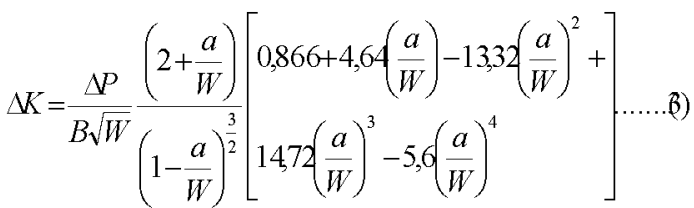

$$
\begin{aligned}
& \Delta P=P_{\max }-P_{\min } \ldots . .(4) \\
& \text { dengan } \\
& \text { a = panjang retak } \\
& \mathrm{N}=\text { jumlah siklus } \\
& \mathrm{C}, \mathrm{n}=\text { konstanta Paris } \\
& \Delta \mathrm{K}=\text { beda faktor intensitas tegangan } \\
& \mathrm{P} \quad=\text { beban } \\
& \mathrm{W} \quad=\text { lebar benda uji } \\
& \mathrm{B} \quad=\text { tebal benda uji }
\end{aligned}
$$

Al 7050 aluminum alloy dengan tipe $7 \mathrm{xxx}$ adalah jenis aluminum high-strength alloy melalui proses tempa, dengan paduan zinc yang biasanya dikombinasikan dengan magnesium untuk penguat pada proses heat treatment [3]. Menempati peringkat tertinggi machinability dibanding aluminum alloy yang lain pada kondisi age-hardened atau full-hardened, memiliki berat jenis yang rendah dan kekuatan yang tinggi terhadap rasio beratnya, serta konduktansi kalor dan listrik yang baik.

Shot peening merupakan perlakuan permukaan yang diaplikasikan pada jenis material logam baik terpisah atau setelah sebelumnya dilakukan plating, hard anodizing, dll., yang akan menghasilkan tegangan sisa, meningkatkan kekerasan dan life time, dalam rangka meningkatkan kekuatan mekanis terhadap beban fatik.

Černý melakukan pengujian untuk mengetahui pengaruh shot peening terhadap inisiasi dan perambatan fisik yang pendek dari retak fatik pada material struktur pesawat terbang, V-95 Al-alloy (sama dengan Al 7075). Digunakan metode direct current potential drop (DCPD) yang mampu mendeteksi celah pendek retakan sekitar 0,2 $\mathrm{mm}$ hingga retak panjang suatu spesimen. Parameter yang digunakan adalah Balottini ukuran 0,43-0,7 $\mathrm{mm}$ dan 0,21-0,32 $\mathrm{mm}$ masing-masing untuk kelompok pertama dan kelompok kedua; dengan intensitas
Almen $\mathrm{A}=0,25$ dan $\mathrm{A}=0,14$; sudut impact $60^{\circ}$ dan $200 \%$ coverage untuk kedua kelompok. Hasil pengamatan fatigue life setelah diaplikasikan shot peening dibandingkan dengan spesimen tanpa shot peening, menunjukkan siklus untuk failure dari spesimen dengan perlakuan shot peening jauh lebih tinggi [4].

Giummarra dan Zonker membandingkan pengaruh beberapa proses surface treatment terhadap ketahanan siklus beban fretting fatigue, termasuk kedalamnya chromic acid anodizing (CAA), shot peening serta shot peening and CAA. Spesimen Al 7085T7651 dengan bentuk low load transfer joint (LLT joint) dan fretting fatigue specimen, ditreatment CAA dengan parameter waktu 40 menit, suhu $40^{\circ} \mathrm{C}$ dan tegangan 0-50 Ramp, dengan ketebalan lebih dari $2153 \mathrm{mg} / \mathrm{sq} \mathrm{m}$ berdasarkan standar original equipment manufacturers (OEMs). Sedangkan untuk parameter shot peening mengikuti standar Metal Improvement Company (MIC) $100 \%$ coverage, 230-280 cast shot, dan intensitas Almen 0,005 A. Pengaruh beberapa proses surface treatment terhadap rata-rata fretting fatigue life. Shot peening dan CAA menempati posisi tertinggi ketahanan terhadap siklus beban fretting fatigue [5].

Diep at. all meneliti pengaruh intensitas Almen dari proses shot peening dengan mesin manual terhadap fatigue life $\mathrm{Al} 7050$ T7451. Spesimen uji fatik dibentuk menyesuaikan dengan pengujian reversed rotation bending $\mathrm{R}=-1$, dengan target range siklus $10^{4}-10^{6}$ dan maksimum stress 310 $\mathrm{MPa}$, dengan kecepatan rotasi $1200 \mathrm{RPM}$. Pengaruh shot peening yang paling besar terhadap fatigue life terjadi pada intensitas $0,1 \mathrm{mmA}-0,15 \mathrm{mmA}$. Fatigue life menurun, apabila intensitasnya meningkat hingga $0,25 \mathrm{mmA}$. Meningkatnya intensitas shot peening akan meningkatkan kekasaran permukaan dan menurunkan ketahanan fatik [6].

Ardianto melakukan pengujian fatik pada spesimen Al 7050-T7651 dengan bentuk CTS (compact test specimen) ASTM E647, perlakuan shot peening menggunakan jenis shot dari bahan steel dan shot size dengan diameter 0,017" dan intensitas Almen 0,006 A di plant area Shot Peening PT. Dirgantara 
Indonesia, dengan mesin manual. Uji fatik dibebani sekitar $11 \%$ dari tegangan tarik maksimum (spesimen standar ASTM E8M) yang dihubungkan dengan analisis beban kombinasi, dengan stress ratio $\mathrm{R}=0,1$. Hasil uji perambatan retak fatik pada spesimen $\mathrm{AR}$ as received material-tanpa perlakuan menghasilkan angka konstanta Paris $\mathrm{A}=1,288 \times 10^{-9}$ dan $\mathrm{n}=2,02$ dan BMSP base metal shot peened-manual machine dengan $\mathrm{A}=1,286 \times 10^{-9}$ dan $\mathrm{n}=2,01$ [7].

Rumusan masalah yang diteliti oleh penulis pada penelitian ini adalah untuk mempelajari pengaruh proses shot peening mesin otomatis pada material pesawat produk PT. Dirgantara Indonesia jenis Al 7050-T7651 terhadap laju perambatan retak fatik dan membandingkannya dengan hasil penelitian sebelumnya.

\section{Metode Penelitian}

Spesimen yang dipakai pada penelitian ini adalah Al 7050-T7651, dari Direktorat Aerostructure PT. Dirgantara Indonesia. Spesimen uji tarik berdasarkan standar ASTM E8M, sedangkan spesimen yang akan digunakan dalam pengujian perambatan retak adalah benda uji WOL (wedge opening loading) yang sekarang dikenal dengan CTS (compact test specimen) berdasarkan ASTM E647 jenis L$\mathrm{T}[8]$.

Proses shot peening mesin otomatis dilakukan di Direktorat Aerostructure, Sub Direktorat Surface Treatment PT. Dirgantara Indonesia dengan parameter sebagai berikut :

Material Shot : Steel

Diameter shot ball : 0,017 inch

Shot flow $\quad: 30 \%$

Tekanan : 3 bar

Intensitas Almen : 0,0082 A

Jarak tembak $: 100 \mathrm{~mm}$

Sudut tembak : $90^{\circ}$

Sedangkan proses pengujian fatik dilakukan di Lab. Material Departemen Teknik Mesin dan Industri DTMI FT UGM dengan mesin servopulser

Merk

: Shimadzu

Jenis mesin : Mesin Servopulser Model : 4825

Pengamatan retak : microscope travelling optic dengan parameter pembebanan $200 \mathrm{~kg}(11 \%$ dari beban ultimate pengujian tarik) dan $\mathrm{R}=0,1$.

Uji perambatan retak fatik dilakukan dengan mengamati setiap pertambahan panjang retak yang terjadi pada sisi depan spesimen $\left(a_{i}\right)$, dimana data-data tersebut digunakan untuk melihat hubungan antara pertambahan panjang retak $(a)$ dan jumlah siklus $(N)$, diolah menggunakan metode incremental polynomial untuk mendapatkan hubungan $\mathrm{da} / \mathrm{dN}-\Delta \mathrm{K}$. Trendline hubungan $\mathrm{da} / \mathrm{dN}-\Delta \mathrm{K}$ diperoleh dengan cara membuat grafik dengan skala log pada da/dN dan $\Delta \mathrm{K}$, sehingga diperoleh persamaan garis yang dapat digunakan untuk menentukan karakteristik perambatan retak fatik (konstanta Paris A dan n).

3. Hasil dan Pembahasan

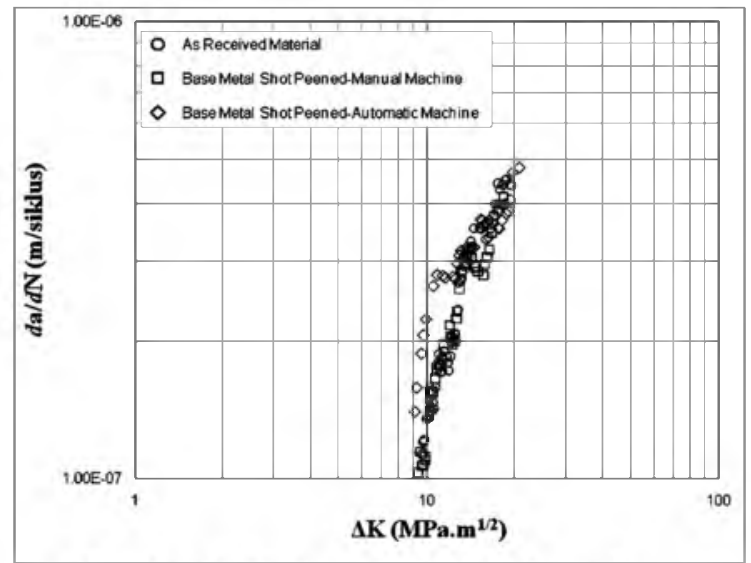

Gambar 2. Hubungan da/dN dan $\Delta \mathrm{K}$

Gambar 2 dan 3 serta Tabel 1, menunjukkan perbandingan sebaran data, trendline dan konstanta Paris.

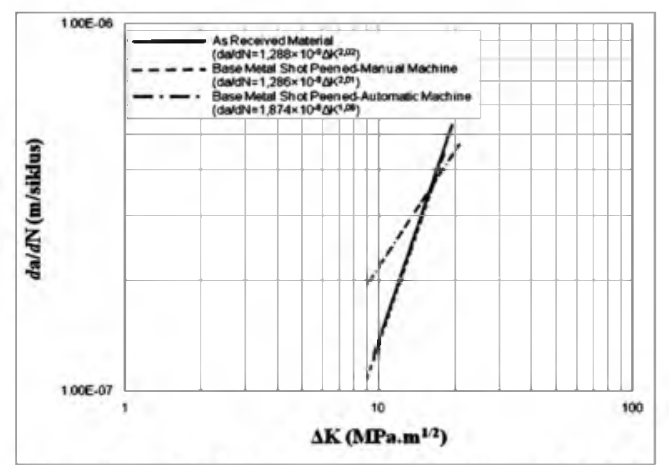

Gambar 3. Hubungan da/dN dan $\Delta \mathrm{K}$ dalam trendline 
Tabel 1. Hasil pengujian perambatan retak fatik Al 7050-T7651

\begin{tabular}{|l|c|c|}
\hline \multirow{2}{*}{ Kategori } & \multicolumn{2}{c|}{ Konstanta Paris } \\
\cline { 2 - 3 } & $\mathrm{A}$ & $\mathrm{n}$ \\
\hline $\begin{array}{l}\text { As Received Material } \\
\text { (AR) }\end{array}$ & $\begin{array}{c}1,288 \times 10^{-} \\
9\end{array}$ & 2,02 \\
\hline $\begin{array}{l}\text { Base Metal Shot } \\
\text { Peened-Manual } \\
\text { Machine (BMSP) }\end{array}$ & $\begin{array}{c}1,286 \times 10^{-} \\
9\end{array}$ & 2,01 \\
\hline $\begin{array}{l}\text { Base Metal Shot } \\
\text { Peened-Automatic } \\
\text { Machine (BMSPA) }\end{array}$ & $\begin{array}{c}1,874 \times 10^{-} \\
8\end{array}$ & 1,06 \\
\hline
\end{tabular}

dari penelitian sebelumnya yang dilakukan oleh Ardianto, antara material AR dan BMSP dengan penelitian terbaru BMSPA. Tampak bahwa sebaran data dan posisi trendline BMSPA berada diatas dari AR dan BMSP, hal ini ditunjukkan pula dari konstanta Paris A-nya lebih tinggi. Meskipun demikian, dalam hal gradien garis untuk trendline BMSPA lebih rendah atau lebih landai dibanding AR dan BMSP, hal ini sesuai dengan kontanta Paris-n untuk BMSPA yang lebih rendah dari pada AR dan BMSP.

Sehingga dapat dinyatakan bahwa perlakuan shot peening dengan mesin otomatis lebih efektif menurunkan laju perambatan retak fatik dari pada mesin manual. Semakin rendah kontanta Paris $\mathrm{da} / \mathrm{dN}$ dan $\Delta \mathrm{K}$ menunjukkan semakin rendahnya laju perambatan retak fatik

\section{Kesimpulan}

Perlakuan shot peening mesin otomatis efektif menurunkan laju perambatan retak fatik, dengan konstanta Paris $1,874 \times 10^{-8}$ dan 1,06 .

\section{Saran}

Perlu dilakukan penelitian lanjutan untuk mengidentifikasi tingkat kekerasan permukaan, kedalaman lapisan tekan dan tegangan sisa yang ditimbulkan dari perlakuan shot peening mesin otomatis, sehingga bisa dianalisis hal yang membuat sebaran data hubungan $\mathrm{da} / \mathrm{dN}$ dan $\Delta \mathrm{K}$ material dengan perlakuan shot peening mesin otomatis sedikit diatas sebaran data hubungan $\mathrm{da} / \mathrm{dN}$ dan $\Delta \mathrm{K}$ material tanpa perlakuan dan dengan perlakuan shot peening mesin manual.

6. Ucapan Terima kasih

Penulis mengucapkan terima kasih kepada Direktorat Riset dan Pengabdian Masyarakat; Direktorat Jenderal Penguatan Riset dan Pengembangan; Kementerian Riset, Teknologi, dan Pendidikan Tinggi yang telah memberi dukungan finansial terhadap penelitian ini.

\section{DAFTAR PUSTAKA}

[1] Starke, E.A.Jr., Staley, J.T., 1996, Application of Modern Aluminum Alloys to Aircraft, Elsevier Science Ltd. Prog. Aerospace Sci. Vol. 32, pp. 131-172.

[2]ASTM Designation : E647-00 Standard Test Method for Measurement of Fatigue Crack Growth Rates. ASTM, 100 Barr Harbor Drive, West Conshohocken, PA 19428-2959, United States.

[3] Brady, G.S., Clauser, H.R., Vaccari, J.A., Materials Handbook, $15^{\text {th }} \mathrm{Ed}$, McGraw-hill.

[4] Cerný, I., 2011, Growth and Retardation of Physically Short Fatigue Cracks in An Aircraft Al-alloy after Shot Peening, Procedia Engineering 10, 3411-3416.

[5] Giummarra, C., Zonker, H.R., 2005, Improving The Fatigue Response of Aerospace Structural Joints, ICAF 2005 Preceedings, Hamburg Germany.

[6] Diep, H., Bae, H., Ramulu, M., 2011, Manual Shot Peening Intensity and Coverage Effects on Fatigue Performance of Aluminum Alloy, Conf Proc 2011: ICSP-11, South Bend, IN USA.

[7] Ardianto, H., Iswanto, P.T., 2015, Pengaruh Shot Peening dan Chromic Acid Anodizing pada Material Pesawat Terbang Al 7050-T7651 terhadap Laju Perambatan Retak Fatik, Jurnal Teknika STTKD, Vol.2 No. 1, 1-11, http://sttkd.ac.id/jurnal/index.php/JT/a rticle/view/43/12. 
[8] ASTM International, 1997, Standard Test Method for Plane-Strain Fracture
Toughness of Metallic Materials, USA. 